\title{
DIGITAL PHYSICALITY: PRINTMAKING
}

\author{
Isaac Kerlow \\ Nanyang Technological University \\ School of Art, Design and Media \\ Earth Observatory of Singapore \\ Singapore \\ ikerlow@gmail.com
}

This short paper revisits a few aspects of digital physicality in my experimentation with computer-aided printmaking during the 1980s and early 1990s. Topics include integration of hand-made and computer-generated, programmed and serendipitous, and output with a variety of traditional and digital printmaking techniques. My artwork in media other than printmaking is not addressed in this paper

\section{INTRODUCTION}

In 1980 I was a young artist fortunate enough to land a student internship in a computer graphics research lab at Columbia University in New York City. This allowed me to get close to computers at a time when they were bulky, unfriendly, and cumbersome. Up to that point I had been trained in the traditional and media arts, had experimented with animation and video, and had gained some recognition in the field of painting. I found computers intriguing, possibly because of my love for science fiction, and decided to learn how to use them. My ultimate and ideal goal was to somehow find a way to integrate computers into my artwork, even though the only reasonable way to output digital creations at the time was by using those noisy black and white dot matrix printers that are almost extinct today.

I decided to teach myself programming and that proved worthy, as I gained useful insights into the techniques and inner workings of the system. I also learned the process for sculpting virtual objects developed at that particular computer graphics research lab. The basic idea was to define 2D contours that were placed in 3D space and then reconstructed with software. The modelling process was laborious but it made use of a huge graphics tablet and that I liked. The process allowed the modelling of shape and surface irregularities and it did not follow the more common geometry-based approach. I liked that too. The particular computer system in use at the research lab was considered high-end, and consisted of a DEC VAX 11/780 with a 24-bit color frame buffer and an E\&S PSII vector system. The modelling and rendering techniques that I used in the early 1980s are documented in [1]. 


\section{CAT 2010 London Conference $\sim 3^{\text {rd }}$ February \\ Isaac Kerlow}

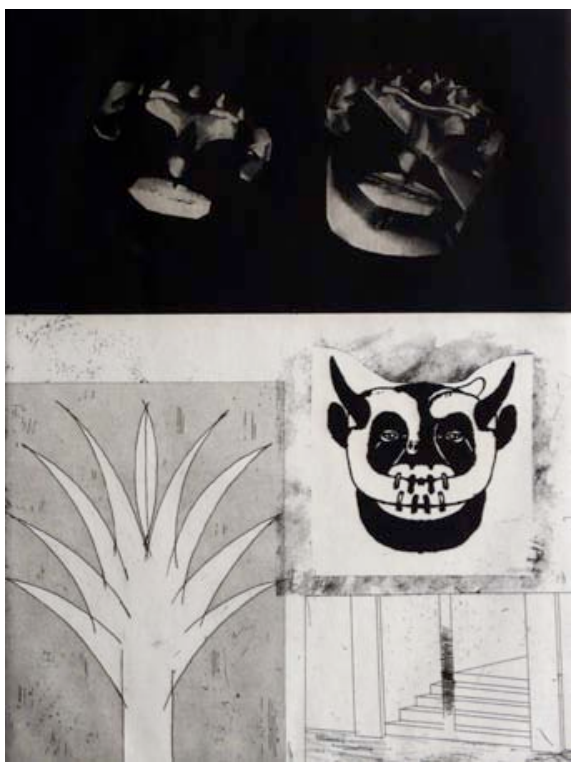

Figure 1. Pyramid in Black and White Number Six, 1985, etching, 51 x $40 \mathrm{~cm}$.

I experimented with a few ways to incorporate the images created with the computer system into my artistic vocabulary. I also wanted to continue working with some of the traditional techniques that I had been using until then, and that remained a guiding thought as I explored with the new digital technology. I particularly liked the procedural approach of working with computers, and incorporated that into my creative process. Cynthia Goodman, Program Director IBM Gallery of Science and Art at the time, said of my working process: "In spite of his intense involvement with computer-generated imagery, the realization of these images in traditional art forms is central to both his working process and his success. Through his skilful integration of images created on computers with others which have been either hand-drawn or painted, Kerlow has demonstrated how electronically-generated imagery offers not only an end product but also a point of departure for a creative mind" [2].

While at the computer lab I experimented with different ways of capturing the imagery that I was creating with the computer system. I tried all the imaging techniques available to me there, as I was interested in finding out about the different visual signatures and degrees of fidelity that were inherent to each. Dot matrix printers yielded a high-contrast black and white image that immediately made me think of the type of high-contrast imagery that I had previously used in graphic arts projects. Electrostatic printers delivered a sort of a black and white halftone printout that was detailed enough to preserve some of the pixels in the color computer-generated image. The software I was using at the time was not suitable for producing four-color separations but I created 


\section{CAT 2010 London Conference $\sim 3^{\text {rd }}$ February \\ Isaac Kerlow}

simple spot color separation techniques by manipulating the color look-up tables in the rendering software. I also took photographs directly off the screen by using a tripod and turning the ceiling lights off to minimize reflection and glare on the monitor. Through trial and error I became proficient at photographing the vector display on high-contrast film and the raster display on color transparency film. I obtained good quality film transparencies that I could further manipulate in the darkroom, as these were years before the release of the Photoshop software in 1990.

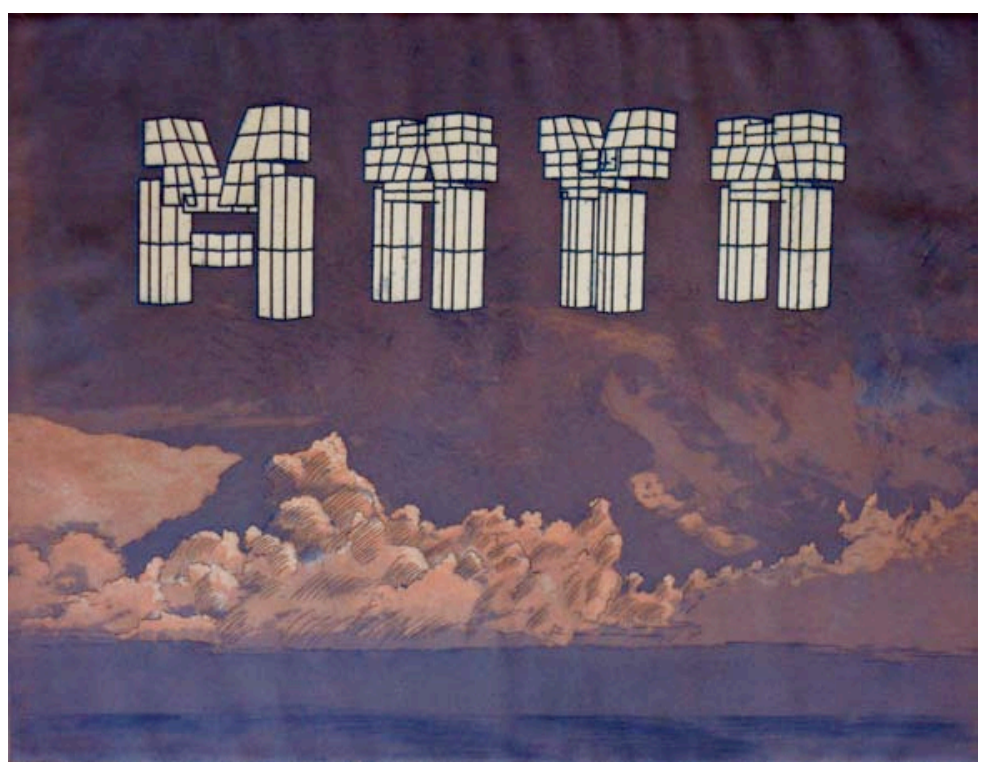

Figure 2. Maya in the Clouds, 1986, etching, $48 \times 67 \mathrm{~cm}$.

After a couple of years of experimentation in the computer lab and in my studio I decided to put together a series of prints where I could apply the techniques that I had developed. I was eager to get busy as I was not aware of anyone working with the same approach of integrating hand-made and computer-generated images. I started working on a series centered around pre-Columbian patterns, fantastic characters and natural elements. Pre-Columbian architecture has been a favorite interest of mine, and I was struck then by the similarity between the jagged edges of low-resolution computer displays and those of stone architectural ornaments found primarily in Mayan and Mixtec pyramids [3]. Through research and previous familiarity with the topic I also found interesting parallelisms between the colourful patterns of hand-made Maya textiles and the textures that I was able to create with the software at my disposal. 


\section{CAT 2010 London Conference $\sim 3^{\text {rd }}$ February \\ Isaac Kerlow}

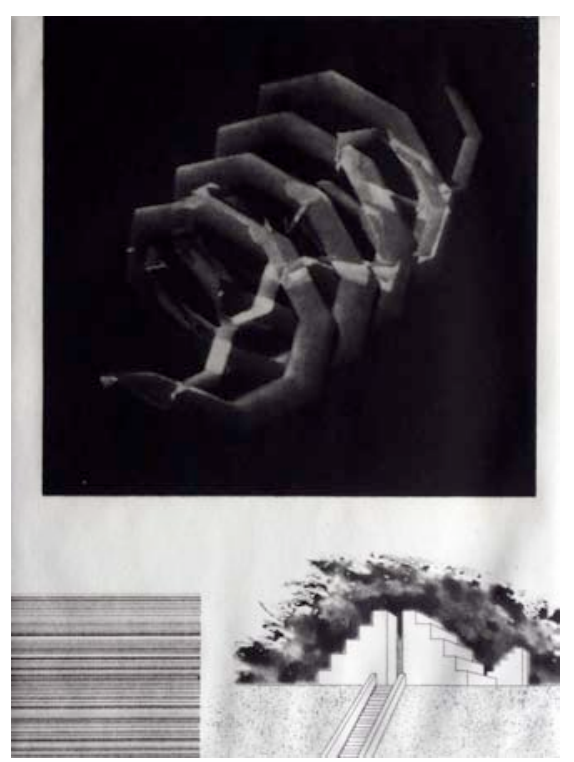

Figure 3. Pyramid in Black and White Number Five, 1985, etching, 51 x $40 \mathrm{~cm}$.

\section{TRANSFERRING THE COMPUTER IMAGES ONTO A PLATE}

The image and archival quality of digital prints in the mid-1980s left a lot to be desired, so I focused my attention on ways to transfer the computer images onto traditional printmaking techniques. "There is a strong conceptual similarity between traditional printmaking and computer image generation. Both techniques are based on the idea of making multiple copies from a single matrix. Traditional printmaking techniques use one or several printing plates, and computers use the numerical description of an image as a matrix for producing multiple versions. It seemed natural to me to transfer the results of a numerical matrix onto a printmaking matrix for creating new versions of the same image" [4].

I decided to stay away from using graphic arts half-toning when transferring the computer images onto traditional printmaking techniques. After a couple of years of experimentation in the computer lab and in my studio I chose to use etching and aquatint techniques. "Pyramids in Black and White" is the seven-etching series that I completed in 1985 (Figs. 1 and 3) and printed on Rives Heavyweight paper. The transfer of the computer images onto the plate was done using photo-etching techniques, and I used the finest possible aquatint in order to obtain the richest black tones. Printing from such dense aquatints became a bit of a challenge while on the press but in the end I was very satisfied with the final quality. Soon thereafter I produced a few color etchings using spot color separation techniques. "Maya on the Clouds," for example, features a 
high-contrast rendering of a morphed alphabet inspired by Mayan architecture floating on a two-color landscape of clouds (Fig. 2).

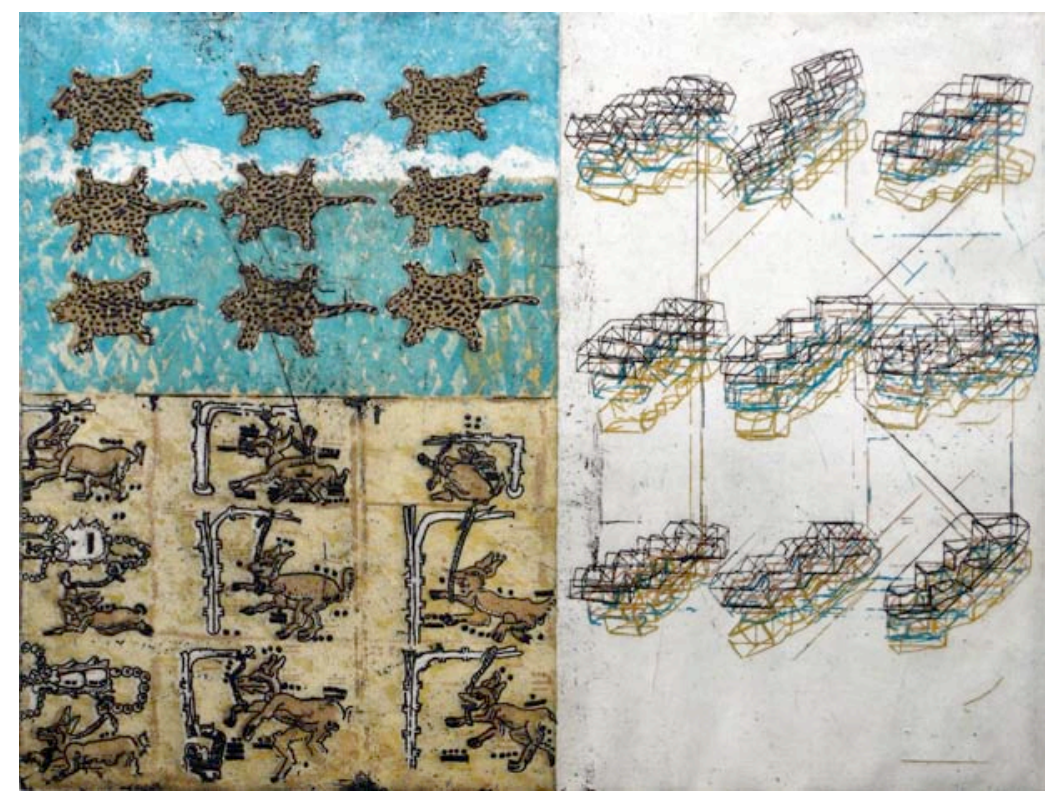

Figure 4. Freedom and Imprisonment, 1986, etching, 48 x $67 \mathrm{~cm}$.

\section{THE SECOND WAVE OF EXPERIMENTATION}

Integrating digital and hand-made elements was at the heart of my experimentation with computer-aided printmaking. Cynthia Goodman and Juan Villoro observed about my integration approach. "Never content to use any medium in a straightforward manner, Kerlow's collage-like intermingling of different media-the hand-drawn with the computer-plotted and the hand-painted with the computer synthesized-causes one to revise one's opinion of each. Furthermore, some of his most sophisticated patterns were computer-generated and/or mechanically plotted and some of his most photographically precise images were either drawn or painted by hand" [2]. "What originates from a brush and what originates from a computer? To ask this is as absurd as trying to hear applause made with only one hand. A master of disguise, Kerlow makes the electric pencil act temperamentally and paints by hand with a precision that the inexperienced eye would attribute to the computer" [5]. 


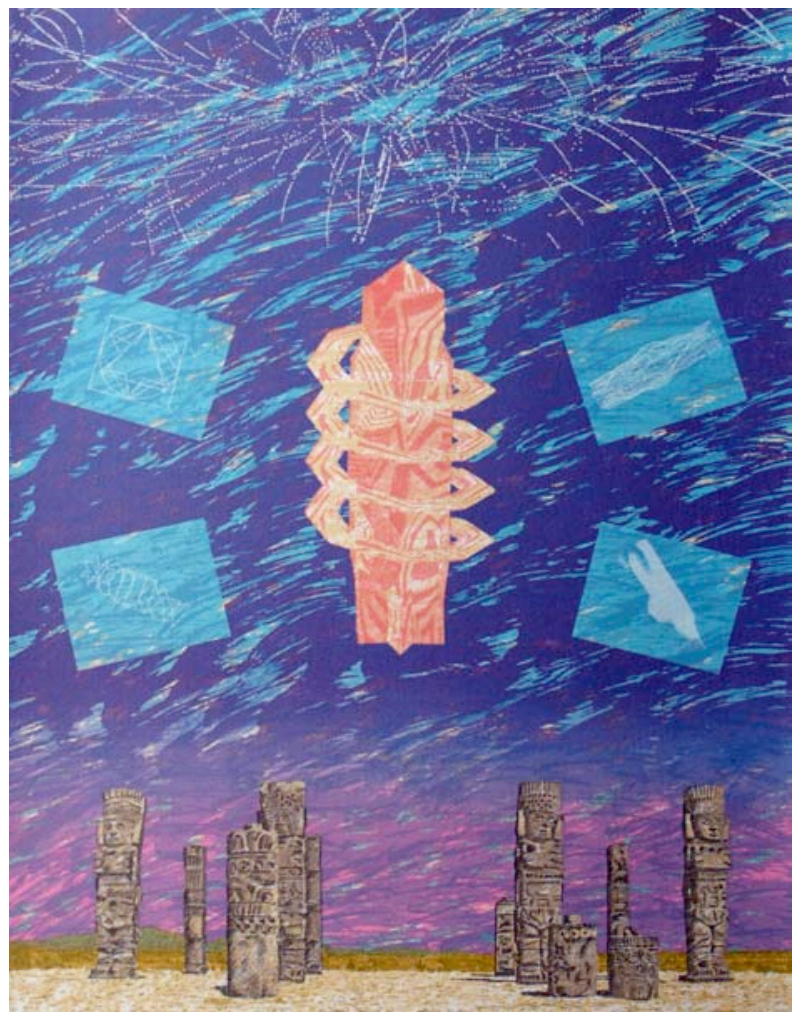

Figure 5. The Big Spiral, 1986, silkscreen, 76 x $56 \mathrm{~cm}$.

After producing a dozen prints I was quite comfortable with photo-etching techniques, and wanted to venture into non-photographic and more direct ways of transferring the computer-generated image onto the plate. I experimented with commercial computercontrolled engraving machines but was not satisfied with the results, so I modified a computer-controlled flatbed pen plotter with a steel needle instead of a pen. This allowed for the computer-generated image to be drawn directly on varnished metal plates, and be etched with an acid solution. The metal needle sometimes got stuck a bit on the metal plate and created a slightly wiggly line. I welcomed this technical imperfection as I missed some of the accidents that normally happen when working with traditional media. I wrote at the time "I am not attracted to the computer because of its capability of creating perfection or pure geometry. My interest in computers is to generate emotional works with a gestural unpolished quality to them" [4]. I also tried replicating the dry point technique with the needle plotter but the mechanism lacked the weight and power required to do it in a consistent and somewhat controllable way. "Freedom and Imprisonment" is a four-color etching where the right half of the work was plotted directly onto four cooper plates (Fig. 4). The work is loaded with poetical contradiction: the jaguar skins flying above the jungle are a metaphor for freedom yet the actual animals are dead in a real sense, while the deer below are trapped yet alive. 


\section{CAT 2010 London Conference $\sim 3^{\text {rd }}$ February \\ Isaac Kerlow}

After the initial period of extreme attention to technical detail I explored simpler and more direct ways to transfer wireframe computer imagery onto etching plates smaller than the sizes that I was used to. I also worked with silkscreen techniques and produced a set of three technically ambitious and successful prints. These incorporated 2D and 3D computer-generated elements and hand-drawn images. They were printed on Arches 300 gr. paper, using transparent and opaque inks. During this time period I also continued to develop my artwork in the form of paintings inspired by or incorporating computer-generated imagery, and computer-based interactive installations [11]. My computer-aided printmaking methodology and techniques from this period are described in [6, 7 and 10] and reviewed in [8,9 and 12].

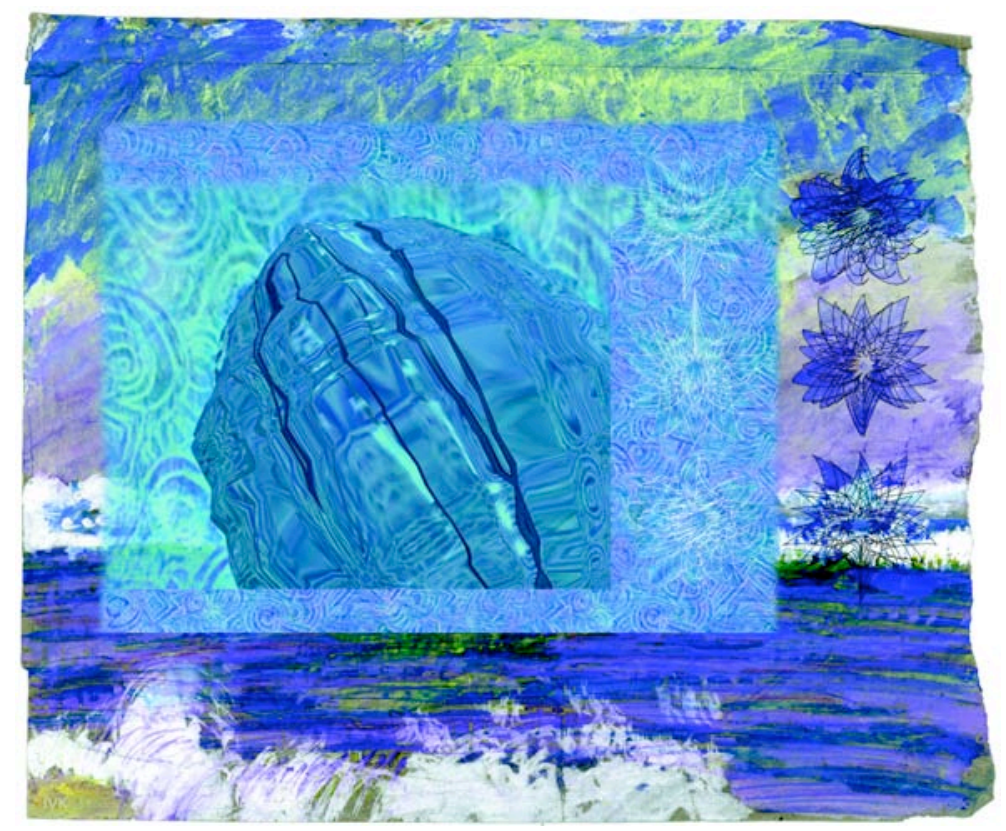

Figure 6. Blue Pearl, 1998, digital print (inkjet), 28 x $34 \mathrm{~cm}$.

In the early 1990s I started to use digital printers to edition my work. It was challenging at first due to the limited image and color resolutions, as well as the ultraviolet weakness of inks and pigments. But things improved with time and I ended up working extensively with dye sublimation and inkjet printers, although I am still interested in using traditional printmaking techniques. I editioned my entire "Broken Heart" project on a Kodak XL 7700 continuous tone digital printer on Ektatherm paper [13]. "Blue Pearl" is an inkjet digital print representative of my work from later that decade, the imagery depicts painted patterns distorted by a transparent virtual object (Fig. 6). 
CAT 2010 London Conference $\sim 3^{\text {rd }}$ February

Isaac Kerlow

\section{ACKNOWLEDGEMENTS}

I want to thank the following individuals for their contribution to my computer-aided printmaking work: Dr Irwin Sobel for facilitating my student internship at the Columbia University Biology Graphics Lab; Paul Marcus the master printer at Pycus Studio in New York for his uncompromising quality; Enrique Cataneo the master printer at Ediciones Multiarte in Mexico City for his flexibility and willingness to experiment; Cynthia Goodman and Juan Villoro for their insightful observations; Vicente Rojo and Albert Ràfols-Casamada for their early encouragement; the former Eastman Kodak Center for Creative Imaging in Camden, Maine for providing digital printing support; and Rosa Maria Malet and Oscar Urrutia for showing my earliest computer-generated artwork at the Joan Miró Foundation in Barcelona in 1985 and the Museum of Modern Art in Mexico City in 1986, respectively.

\section{References}

[1] KERLOW, I: The Computer as an Artistic Tool. 1984, Byte, Sep., pp. 189-206.

[2] GOODMAN, C: Mexican Myths with Modern Technology. 1986, Museum of Modern Art, Mexico City, exhibition catalog, pp. 2-4.

[3] KERLOW, I: Computer Image Generation of Pre-Columbian Shapes and Patterns. 1986, Leonardo Journal, The International Society for the Arts, Sciences and Technology, Vol. 19 Num. 2, pp. 131-134.

[4] KERLOW, I: Digital Pioneers. 1998, SIGGRAPH 98 Art Show. Orlando, Florida, exhibition catalog.

[5] VILlORO, J: Ventanas de la luz más rápida. 1988, Obelisco, Mexico City, vol. 2 num. 19, p. 5.

[6] KERLOW, I: Computer-Aided Printmaking. 1985, Proceedings of the Fifth Symposium on Small Computers in the Arts, Philadelphia, pp. 57-64.

[7] KERLOW, I: Computer-Generated Images and Traditional Printmaking. 1988, Visual Computer, Germany, Vol. 4 Num. 1, pp. 8-18.

[8] ROSS, J et al: The Complete Printmaker. 1989, MACMILLAN PUBLISHING, New York, pp. 276-277.

[9] WHALE, G: Digital Printmaking. 2001, A\&C BLACK, London, pp. 72 and 76.

[10] KERLOW, I: Computers, Pyramids and Hearts. 1994, Contemporary Impressions Journal, AMERICAN PRINT ALLIANCE, Vol. 2 Num. 2.

[11] GOODMAN, C: Digital Visions, Computers and Art. 1987, HARRY ABRAMS, New York, pp. 108-109.

[12] WANDS, B: Art in the Digital Age. 2006, THAMES AND HUDSON, London, p. 54.

[13] KERLOW, I: Broken Heart. 1992, Museo Nacional de la Estampa, Mexico City, exhibition catalog. 